\title{
Effect of chromoendoscopy in the proximal colon on colorectal neoplasia detection in Lynch syndrome: a multicenter randomized controlled trial
}

\author{
Jasmijn F. Haanstra, MD, ${ }^{1,6}$ Evelien Dekker, MD, PhD, ${ }^{2}$ Annemieke Cats, MD, PhD, ${ }^{3}$ \\ Fokko M. Nagengast, MD, PhD, ${ }^{4}$ James C. Hardwick, MD, PhD, ${ }^{5}$ Steven A. Vanhoutvin, MD, PhD, ${ }^{3}$ \\ Wouter H. de Vos tot Nederveen Cappel, MD, PhD, ${ }^{6}$ Hans F. Vasen, MD, PhD, ${ }^{5,7}$ \\ Jan H. Kleibeuker, MD, PhD, ${ }^{1}$ Jan J. Koornstra, MD, PhD ${ }^{1}$
}

Groningen, Amsterdam, Nijmegen, Leiden, Zwolle, the Netherlands

\begin{abstract}
Background and Aims: Patients with Lynch syndrome (LS) undergo regular surveillance by colonoscopy because of an increased risk of colorectal neoplasia, particularly in the proximal colon. Chromoendoscopy (CE) has been reported to improve neoplasia detection compared with conventional white-light endoscopy (WLE), but evidence is limited. Our aim was to investigate the effect of CE in the proximal colon on detection of neoplastic lesions during surveillance in LS.
\end{abstract}

Methods: This was a multicenter prospective randomized controlled trial of 246 patients with LS who were randomly assigned $(1: 1)$ to conventional WLE $(\mathrm{n}=123)$ or colonoscopy with CE in the proximal colon $(\mathrm{n}=$ 123), stratified for previous colorectal adenomas and enrolling center. Two years after baseline colonoscopy, patients underwent colonoscopy with $\mathrm{CE}$ in the proximal colon. The primary outcome was the proportion of patients with at least one neoplastic lesion at baseline and after 2 years.

Results: Neoplasia detection rates at baseline colonoscopy were 27\% for WLE versus 30\% for CE (odds ratio [OR], 1.23; 95\% confidence interval $[\mathrm{CI}], 0.69-2.2 ; P=.56$ ). In the proximal colon, neoplasia detection rates were $16 \%$ for WLE versus 24\% for CE (OR, 1.6; 95\% CI, 0.9-3.1; $P=.13$ ). Total procedure time was 9 minutes longer in the CE group. At follow-up after 2 years, neoplasia detection rates were similar in both groups: $26 \%$ for the original WLE group versus $28 \%$ for the CE group (OR, $1.1 ; P=.81$ ).

Conclusions: CE in the proximal colon for LS surveillance was not superior to WLE with respect to the initial detection of neoplasia, and not associated with reduced neoplasia detection rates after 2 years. The value of CE remains to be established. (Clinical trial registration number: NCT00905710.) (Gastrointest Endosc 2019;90:624-32.)

\section{INTRODUCTION}

Lynch syndrome (LS) is the most common hereditary colorectal cancer (CRC) syndrome. LS is caused by

\begin{abstract}
Abbreviations: CE, chromoendoscopy; CI, confidence interval; CRC, colorectal cancer; $H D$, high-definition; $I Q R$, interquartile range; $L S$, Lynch syndrome; MMR, mismatch repair; $O R$, odds ratio; $S D$, standard deviation; SSP, sessile serrated polyp; WLE, white-light endoscopy.
\end{abstract}

DISCLOSURE: Dr Dekker has received equipment on loan, a research grant, and bonorarium from FujiFilm; honorarium for consultancy and speaker's fee from Olympus Europe; honorarium for consultancy from Tillots; speaker's fee from Roche; and bonorarium for consultancy and speaker's fee from GI Supply. All authors disclosed no financial relationships relevant to this publication.

Copyright $@ 2019$ by the American Society for Gastrointestinal Endoscopy 0016-5107/\$36.00

https://doi.org/10.1016/j.gie.2019.04.227

Received December 19, 2018. Accepted April 16, 2019. inherited mutations affecting any of 4 DNA mismatch repair (MMR) genes, MSH2, MLH1, PMS2 or MSH6, or by a deletion in the EPCAM gene, which leads to methylation of the adjacent $M S H 2$ promoter. Gene mutation carriers

Current affiliations: Department of Gastroenterology, University Medical Center Groningen, University of Groningen, Groningen (1); Department of Gastroenterology, Academic Medical Center, University of Amsterdam, Amsterdam (2); Department of Gastroenterology, the Netherlands Cancer Institute, Amsterdam (3); Department of Gastroenterology, Radboud University Nijmegen Medical Center, Nijmegen (4); Department of Gastroenterology, Leiden University Medical Center, Leiden (5); Department of Gastroenterology, Isala Clinics, Zwolle (6); The Netherlands Foundation for the Detection of Hereditary Tumours, Leiden, the Netherlands (7).

Reprint requests: Jan J Koornstra, MD PhD, Department of Gastroenterology and Hepatology, University Medical Centre Groningen, PO Box 30001, 9700 RB Groningen, the Netherlands.

If you would like to chat with an author of this article, you may contact Dr Koornstra at j.j.koornstra@umcg.nl. 
have a high risk of developing CRC and various extracolonic malignancies. ${ }^{1,2}$

Regular colonoscopy every 1 to 3 years with removal of adenomatous polyps is universally recommended. Removal of these precursor lesions reduces CRC risk and CRC-related mortality in LS by at least 50\%. ${ }^{3-5}$ Nevertheless, up to $46 \%$ of patients still develop interval CRCs within the recommended surveillance intervals. ${ }^{6} \mathrm{Up}$ to half of adenomas may be missed by surveillance colonoscopy. ${ }^{4,7}$ Compared with patients at average risk for CRC, adenomas in patients with LS are more likely to have a nonpolypoid endoscopic appearance, especially in the proximal colon, and many of these proximal adenomas already show high-grade dysplasia when still small. ${ }^{8,9}$ Because these lesions are easily overlooked, ${ }^{10}$ it is of utmost importance to optimize adenoma detection.

Surveillance in LS is generally performed using whitelight colonoscopy (WLE). In recent years, new endoscopic techniques have been investigated to optimize detection of colorectal neoplasia in LS. ${ }^{11}$ One of these techniques is dye-spray chromoendoscopy (CE). CE is a relatively easy technique without the need for special endoscopes, using topically applied dye spray to facilitate visualization of fine mucosal surface details. ${ }^{12} \mathrm{CE}$ has been shown to increase the detection of neoplasia in the colorectum in the general population, ${ }^{13-15}$ in patients with inflammatory bowel disease, ${ }^{16,17}$ and in patients with LS. ${ }^{7,18-20}$ The European Society of Gastrointestinal Endoscopy recommends the use of CE in LS but acknowledges that the recommendation is based on low-quality evidence. ${ }^{15}$ Previous studies suggest superiority of CE over WLE in the detection of neoplastic lesions, although convincing data are lacking. Drawbacks of CE include a prolonged procedure time, increased detection of clinically irrelevant non-neoplastic lesions, and the need for experience in the technique. Although it is likely that enhancing neoplasia detection in LS using CE will result in a reduction of neoplastic lesions at subsequent procedures, this has never been studied. The aim of the present study was to compare neoplasia detection rates using CE versus WLE in patients with LS under endoscopic surveillance.

\section{METHODS}

\section{Study design and participants}

This study was a prospective randomized controlled parallel trial in 6 centers in the Netherlands. Proven or obligate carriers of an MMR gene mutation in $M L H 1, M S H 2 / E P$ $C A M$, or MSH6 aged between 20 and 70 years of age were eligible. PMS2 mutation carriers were not included because the risk of colorectal neoplasia is much lower in these patients in comparison with carriers of mutations in the other genes. ${ }^{5}$ Exclusion criteria were previous colon surgery or the presence of any psychologic, familial, sociologic, or geographic condition potentially hampering compliance with the study protocol and follow-up schedule. The study protocol was approved by the local medical ethical committee of the University Medical Center Groningen on May 8, 2008, and subsequently in all other participating centers. Patients were recruited between July 2008 and June 2014. The last colonoscopy was performed in May 2016. All participants provided written informed consent.

\section{Randomization and masking}

Patients were enrolled by clinicians of the participating centers. Patients were randomly assigned (1:1) to conventional WLE or colonoscopy using CE. The endoscopic surveillance technique to be used (WLE or CE) was marked and placed in blocks with a fixed size of 10 sealed opaque envelopes that were created in advance. After inclusion and before the procedure, 1 envelope was drawn and opened just before colonoscopy. Randomization was stratified for previous colorectal adenomas and enrolling center. The endoscopists could not be masked to the endoscopic strategy because CE requires the application of dye spray as part of the technique. Twenty-four months after the baseline colonoscopy procedure, all patients underwent colonoscopy with CE. Deviation from the predetermined interval of 24 months was allowed at the discretion of participating endoscopists to a maximum of 6 months, so 18 to 30 months. The study design is shown in Figure 1.

\section{Procedures}

All procedures were performed by experienced gastroenterologists, preferably one dedicated endoscopist in each center, with extensive experience in CE procedures. Cecal intubation was confirmed by documented identification of the ileocecal valve and appendiceal orifice. In the WLE group, the entire colon was examined by white-light colonoscopy. In the CE group, after cecal intubation, a dye-spray catheter was used to spray a $0.4 \%$ indigo carmine solution onto the mucosal surface of the proximal colon. This was performed in segments of $10 \mathrm{~cm}$ during gradual withdrawal from the cecum up to the splenic flexure. The distal colon in the CE group was inspected with conventional WLE.

In both arms, bowel preparation was based on oral lavage using polyethylene glycol electrolyte solution or a similar preparation according to local practice of the institution. To evaluate the quality of bowel preparation, a semiquantitative grading scale was used, as in earlier studies. ${ }^{18,20}$ The overall quality of bowel preparation was rated good (only fluid residues, which could be aspirated, offering $100 \%$ visualization), fair (>90\% visualization), and poor (<90\% visualization). Bowel preparation was considered adequate in patients with good or fair bowel preparation. Patients with poor bowel preparation were excluded from analysis as well as patients in whom the cecum was not reached. A minimal withdrawal time of 6 minutes was considered to be required in line with international 


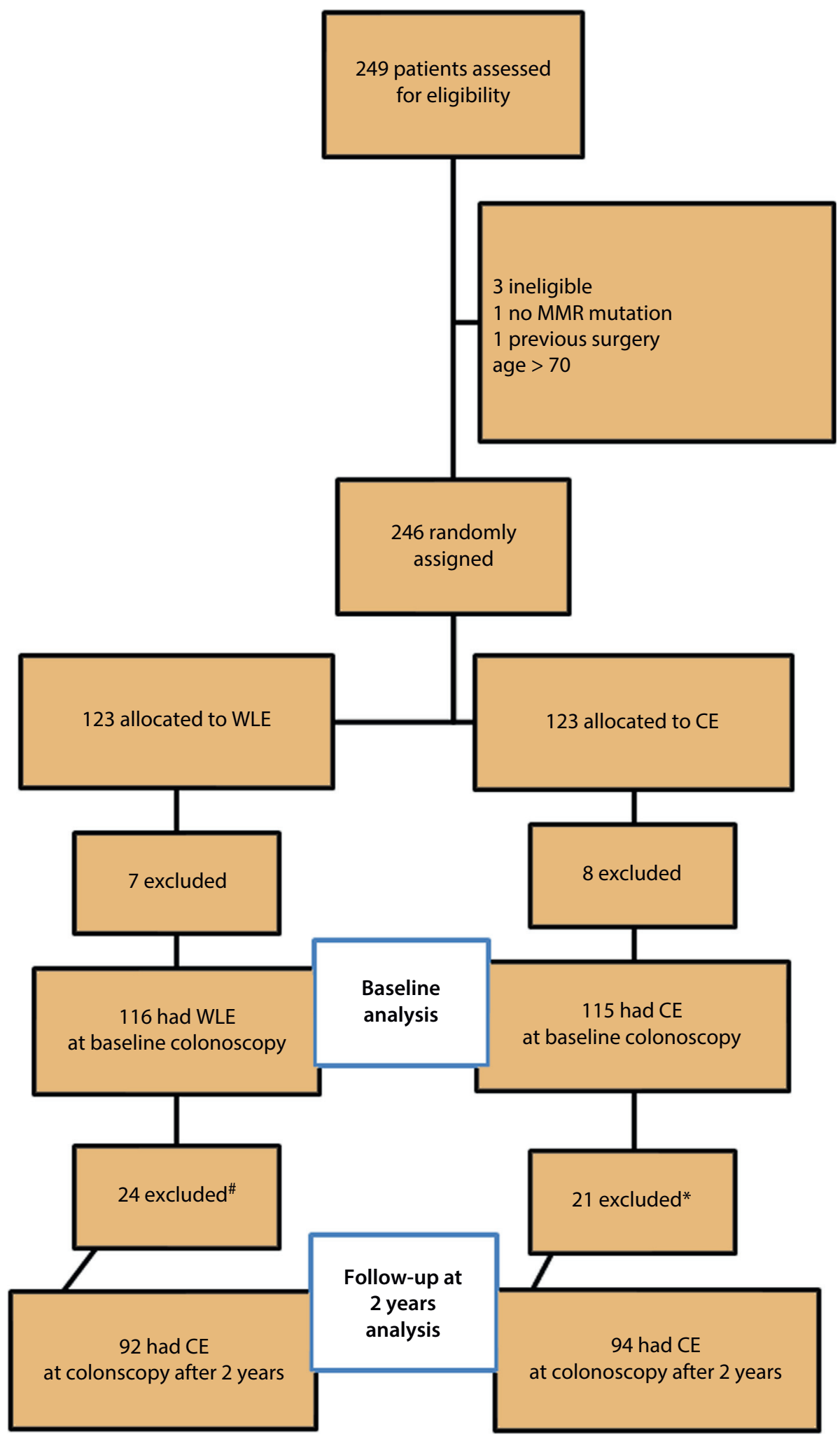

Figure 1. Flowchart showing the study design. ${ }^{\#}$ Reasons for exclusion were colectomy $(n=1)$, severe comorbidity $(n=1)$, death not related to the study $(n=1)$, serious deviation from predefined interval $(n=12)$, and poor bowel preparation $(n=9)$. *Reasons for exclusion were serious deviation from predefined interval $(\mathrm{n}=13)$ and poor bowel preparation $(\mathrm{n}=8)$. CE, Chromoendoscopy; $M M R$, mismatch repair; WLE, white-light endoscopy. 
guidelines. ${ }^{21}$ All lesions identified were classified according to the Paris classification, ${ }^{22}$ size, and segment of the colon. The location of a polyp was considered proximal when the polyp was detected in the part of the colon proximal from the splenic flexure. Lesion size was estimated in millimeters. All amenable lesions were removed by snare polypectomy during procedures and sampled for histopathologic examination. Total procedure time was defined as the time between introduction and extubation of the endoscope. Withdrawal time was defined as the total extubation time, including spraying of indigo carmine minus time spent on polypectomy.

Histologic samples were assessed by a gastrointestinal specialist pathologist at each participating center. A lesion was considered neoplastic if histology showed either adenocarcinoma or adenoma. Adenomas were classified as tubular, tubulovillous, villous, or serrated. The degree of dysplasia in adenomas was classified as low grade or high grade. Adenomas (1) larger than $1 \mathrm{~cm}$; and/or (2) with high-grade dysplasia; and/or (3) with tubulovillous or villous architecture, and adenocarcinomas were considered as advanced neoplasia. A lesion was considered non-neoplastic when histology showed no dysplasia and classified as hyperplastic or serrated (designated sessile serrated polyp [SSP]), lymphoid tissue, or normal mucosa.

\section{Outcomes}

The primary outcome was the proportion of patients with at least 1 neoplastic lesion (neoplasia detection rate) at baseline and at the follow-up colonoscopy after 2 years. Subgroup analysis was performed for findings in the proximal colon. Secondary endpoints were the proportion of patients with one or more polyps (polyp detection rate); mean number of neoplastic lesions per colonoscopy; median procedure times; colectomy rate (defined as the proportion of patients requiring a colectomy), and adverse event rate (defined as the proportion of patients with immediate or delayed postpolypectomy bleeding or perforation).

\section{Statistical analysis}

When WLE was used in patients with LS, the neoplasia detection rate was around $20 \%$ in previous studies $^{3,19,23,24}$ with a 2 -fold increment in detection rate when using pancolonic $\mathrm{CE} .{ }^{18-20}$ Based on these data, we calculated that 91 patients were required in each group (80\% power, 2 -sided $\alpha$ of $5 \%$ ). ${ }^{25}$ No data were available from the literature that allowed us to estimate the yield of $\mathrm{CE}$ in the proximal colon. The aim was to include at least $10 \%$ additional patients in each group to correct for expected drop-out or cases lost to follow-up. Neoplasia detection rates and polyp detection rates were compared using the Fisher exact test with Mantel-Haenszel statistic to estimate odds ratio (OR) and 95\% confidence intervals (CIs). Mean numbers of neoplastic lesions per colonoscopy and median procedure times were compared using the

\begin{tabular}{|c|c|c|}
\hline & $\begin{array}{c}\text { White-light } \\
\text { endoscopy } \\
(n=116)\end{array}$ & $\begin{array}{l}\text { Chromoendoscopy } \\
(n=115)\end{array}$ \\
\hline Age (years), mean (SD) & $46(11)$ & $46(12)$ \\
\hline Male gender, n (\%) & $46(39)$ & $49(43)$ \\
\hline \multicolumn{3}{|l|}{ Mutation type, n (\%) } \\
\hline MLH1 & $26(22)$ & $33(29)$ \\
\hline MSH2 & $40(34)$ & $36(31)$ \\
\hline MSH6 & $49(42)$ & $42(36)$ \\
\hline EPCAM & $1(1)$ & $4(4)$ \\
\hline First colonoscopy & $22(19)$ & $22(19)$ \\
\hline Previous adenoma(s) & $43(37)$ & $46(40)$ \\
\hline
\end{tabular}

$L S$, Lynch syndrome; $S D$, standard deviation.

Mann-Whitney test. Adverse event rates and colectomy rates were compared using the $\chi^{2}$ test. Outcomes at follow-up after 2 years were analyzed on a per protocol basis, defined as the participants in both groups who underwent the assigned intervention, completed both the baseline colonoscopy and the colonoscopy after 2 years, and had no other protocol violations. Two-sided $P$ values of less than .05 were considered statistically significant. All statistical analyses were performed using IBM Statistical Package for the Social Sciences (SPSS) version 23.0.

This study was registered in the ClinicalTrials.gov registry with identifier NCT00905710.

\section{RESULTS}

Between July 22, 2008, and June 27, 2014, 249 patients were assessed for eligibility, and 246 patients fulfilling the inclusion criteria were randomized to undergo WLE $(n=123)$ or $\mathrm{CE}(\mathrm{n}=123)$. After randomization, 15 patients were excluded because of poor bowel preparation or incomplete colonoscopy, leaving a total of 116 patients in the WLE group and 115 patients in the CE group completing the baseline procedure according to the protocol (Fig. 1). Table 1 shows the baseline characteristics, which were similar for the 2 groups. The mean age was 46.0 years (standard deviation $[\mathrm{SD}], 11.5$ years). In both groups, the most common mutation type was MSHG, followed by MSH2 and $M L H 1$. Only a small number of EPCAM mutation carriers were included. For 44 patients (19\%), it was their first colonoscopy. Of the 187 patients who had already undergone one of more colonoscopies before inclusion, 89 (48\%) had 1 or more adenomas on previous occasions.

\section{Baseline colonoscopy}

The baseline procedure characteristics are presented in Table 2 . CE took significantly more time than conventional 


\begin{tabular}{|c|c|c|}
\hline & $\begin{array}{l}\text { White-light } \\
\text { endoscopy } \\
(n=116)\end{array}$ & $\begin{array}{l}\text { Chromoendoscopy } \\
\qquad(\mathrm{n}=115)\end{array}$ \\
\hline $\begin{array}{l}\text { Total procedure time (minutes), } \\
\text { median (IQR) }\end{array}$ & $22(17-30)$ & $31(24-42)$ \\
\hline $\begin{array}{l}\text { Withdrawal time (minutes), } \\
\text { median (IQR) }\end{array}$ & $12(9-16)$ & $19(15-24)$ \\
\hline $\begin{array}{l}\text { High-definition scope used, } \\
\mathrm{n}(\%)^{*}\end{array}$ & $50 / 111(45)$ & $57 / 110(52)$ \\
\hline \multicolumn{3}{|l|}{ Bowel preparation, n (\%) } \\
\hline Good & $92(79)$ & $82(71)$ \\
\hline Fair & $24(21)$ & $33(29)$ \\
\hline Adverse event rate & $1 / 116$ & $1 / 115$ \\
\hline
\end{tabular}

$I Q R$, Interquartile range.

*Data not available for all cases.

colonoscopy, with median total procedure times of 31 minutes versus 22 minutes, respectively (difference 9 minutes, $P<.0001$ ). This was due to a significantly longer withdrawal time: 19 minutes for $\mathrm{CE}$ versus 12 minutes for WLE (difference 7 minutes, $P<.0001$ ). Procedures were performed with a high-definition (HD) colonoscope in $48 \%$ of cases where information regarding the type of endoscopy was available, and this was not different between the groups.

At the baseline procedure, 126 polyps were detected in the WLE group, whereas 145 polyps were removed in the CE group. Detection rates of the baseline procedure are summarized in Table 3, and the histopathologic characteristics of the lesions are presented in Table 4 . The neoplasia detection rate was similar in both groups: $27 \%$ for WLE and 30\% for CE (OR, 1.23; 95\% CI, 0.69-2.2; $P=.56)$. The mean number of neoplastic lesions detected per colonoscopy was 0.39 (SD, 0.72 ) for WLE and $0.50(\mathrm{SD}, 0.95)$ for $\mathrm{CE}(P=.29)$.

As CE was applied only in the proximal colon, a subgroup analysis was performed with respect to location. The polyp detection rate in the proximal colon was higher in the CE group than in the WLE group: $47 \%$ versus $28 \%$ (OR, 2.3; 95\% CI, 1.3-4.0; $P=.003$ ). The neoplasia detection rates in the proximal colon were similar: 28 of 115 (24\%) for CE versus 19 of 116 (16\%) for WLE (OR, 1.6; 95\% CI, 0.9-3.1; $P=.13$ ). The mean number of proximal neoplastic lesions per colonoscopy was $0.22(0.586)$ in the WLE group and $0.38(0.80)$ in the CE group $(P=.08)$.

Overall, 167 non-neoplastic lesions were detected in both groups, mostly SSPs, equally divided between the 2 groups. Most SSPs were found in the distal colon. No SSPs larger than $1 \mathrm{~cm}$ were found in the proximal colon. The use of HD scopes versus non-HD devices was not associated with higher detection rates of polyps, neoplastic lesions, or SSPs (details not shown). Neoplasia detection rates were not statistically different between the 6 centers (Fisher exact test).

\begin{tabular}{lccc}
\hline TABLE 3. Endoscopic detection rates at baseline colonoscopy \\
\hline & $\begin{array}{c}\text { White-light } \\
\text { endoscopy } \\
\text { (n = 116), } \mathbf{n}(\%)\end{array}$ & $\begin{array}{c}\text { Chromoendoscopy } \\
\text { ( } \mathbf{n}=\mathbf{1 1 5}), \\
\mathbf{n}(\%)\end{array}$ & $\begin{array}{c}\boldsymbol{P} \\
\text { value }\end{array}$ \\
\hline $\begin{array}{l}\text { Patients with polyp(s) } \\
59(51)\end{array}$ & $64(56)$ & .46 \\
\hline $\begin{array}{l}\text { Patients with } \\
\text { neoplasia }\end{array}$ & $31(27)$ & $35(30)$ & .56 \\
\hline $\begin{array}{l}\text { Patients with } \\
\text { advanced neoplasia }\end{array}$ & $7(6)$ & $5(4)$ & .43 \\
\hline $\begin{array}{l}\text { Patients with proximal } \\
\text { polyps }\end{array}$ & $32(28)$ & $54(47)$ & .003 \\
\hline $\begin{array}{l}\text { Patients with proximal } \\
\text { neoplasia }\end{array}$ & $19(16)$ & $28(24)$ & .13 \\
\hline
\end{tabular}

\section{Follow-up colonoscopy at 2 years}

Two years after the baseline investigation, colonoscopy with CE was scheduled. For various reasons, 45 patients were excluded at the time of the 2-year colonoscopy (Fig. 1), mainly because of poor bowel preparation or deviation from the predefined interval in the protocol. This resulted in 186 patients completing the entire study protocol: 92 patients from the original WLE group and 94 patients from the original CE group, and these patients were included in the per-protocol analysis. $\mathrm{CE}$ in the proximal colon was applied in these 186 patients at their 2 -year colonoscopy. The median interval between the baseline colonoscopy and the 2-year colonoscopy was 24 months (IQR, 23-25 months).

Procedures were comparable between groups regarding procedure characteristics (Table 5). Median withdrawal time was 18 minutes (IQR, 13-24 minutes), which was similar to the withdrawal time in the $\mathrm{CE}$ group at baseline colonoscopy. HD devices were used in $65 \%$ of patients in the original WLE group and in $70 \%$ in the original CE group (not significant).

Detection rates of the follow-up procedure after 2 years are summarized in Table 6, and the histopathologic characteristics of lesions are presented in Table 7. The polyp detection rate was lower in the original CE group than in the original WLE group: 40\% versus 59\% (OR, 0.48; 95\% CI, 0.27-0.86; $P=.013)$. Neoplasia detection rates were $26 \%$ in the WLE group and $28 \%$ in the CE group (OR, 1.1; 95\% CI, 0.57-2.07; $P=.81$ ). The mean (SD) number of neoplastic lesions detected per colonoscopy was $0.41(0.88)$ in the WLE group and 0.39 $(0.91)$ in the CE group $(P=.88)$. Subgroup analysis was performed according to lesion location. The neoplasia detection rates in the proximal colon were similar between the groups: 22\% for the WLE group versus 22\% in the $\mathrm{CE}$ group. The mean number of proximal neoplastic lesions per colonoscopy was $0.36(0.86)$ in the WLE group and $0.29(0.76)$ in the CE group $(P=.55)$.

Similar to the baseline procedure, detection rates of polyps overall, neoplastic lesions, and SSPs were 


\begin{tabular}{|c|c|c|}
\hline & $\begin{array}{l}\text { White-light } \\
\text { endoscopy } \\
(n=116)\end{array}$ & $\begin{array}{l}\text { Chromoendoscopy } \\
\quad(n=115)\end{array}$ \\
\hline Total number of lesions & 126 & 145 \\
\hline Total number of neoplastic lesions & 46 & 58 \\
\hline \multicolumn{3}{|c|}{ Number of neoplastic lesions according to histology } \\
\hline Adenoma with low-grade dysplasia & 41 & 54 \\
\hline $\begin{array}{l}\text { Adenoma with high-grade } \\
\text { dysplasia }\end{array}$ & 4 & 4 \\
\hline $\begin{array}{l}\text { Adenoma with serrated histology } \\
\text { (traditional serrated adenoma) }\end{array}$ & 0 & 0 \\
\hline Carcinoma & 1 & 0 \\
\hline Advanced neoplastic lesions & 7 & 8 \\
\hline \multicolumn{3}{|c|}{ Number of neoplastic lesions according to location } \\
\hline Proximal & 26 & 44 \\
\hline Distal & 20 & 14 \\
\hline \multicolumn{3}{|l|}{ Number of adenomas according to size } \\
\hline$\leq 5 \mathrm{~mm}$ & 31 & 47 \\
\hline $6-9 \mathrm{~mm}$ & 9 & 10 \\
\hline$\geq 10 \mathrm{~mm}$ & 5 & 1 \\
\hline Number of non-neoplastic lesions & 80 & 87 \\
\hline \multicolumn{3}{|c|}{ Number of non-neoplastic lesions according to histology } \\
\hline Sessile serrated polyps & 54 & 31 \\
\hline Proximal $<5 \mathrm{~mm}$ & 11 & 12 \\
\hline Proximal 5-9 mm & 5 & 2 \\
\hline Proximal $>10 \mathrm{~mm}$ & 0 & 0 \\
\hline Distal & 38 & 17 \\
\hline $\begin{array}{l}\text { Other (lymphoid tissue, normal } \\
\text { mucosa) }\end{array}$ & 26 & 56 \\
\hline
\end{tabular}

comparable in procedures that had been performed with a HD colonoscopy compared with those performed with a non-HD device. The neoplasia detection rates were not statistically different between the 6 centers (Fisher exact test).

At the follow-up procedure, 99 lesions were detected in the original WLE group, whereas 88 lesions were removed in the CE group. CRC was detected in 3 patients in the original $\mathrm{CE}$ group during the procedure after 2 years, whereas only 1 case of CRC was diagnosed in the WLE group. All these CRCs were located in the proximal colon. Patient characteristics of these patients with CRC found during the follow-up procedure are shown in Table 8. In 2 of these 4 patients, the level of bowel preparation was fair during the baseline procedure. Three of these 4 patients had one or more adenomas removed at the baseline procedure. Three of the 4 patients had undergone the baseline procedure with a non-HD device.

Colectomy rates were low in both groups throughout the study period. After the baseline procedure, 1 patient

\begin{tabular}{|c|c|c|}
\hline & $\begin{array}{c}\text { White-light } \\
\text { endoscopy group } \\
(n=92)\end{array}$ & $\begin{array}{c}\text { Chromoendoscopy } \\
\text { group }(n=94)\end{array}$ \\
\hline $\begin{array}{l}\text { Total procedure time } \\
\text { (minutes), median (IQR) }\end{array}$ & $29(20-40)$ & $29(21-38)$ \\
\hline $\begin{array}{l}\text { Withdrawal time (minutes), } \\
\text { median (IQR) }\end{array}$ & $17(13-24)$ & $19(13-24)$ \\
\hline $\begin{array}{l}\text { High-definition scope } \\
\text { used, } \mathrm{n}(\%)^{*}\end{array}$ & $59 / 91(65)$ & $62 / 88(70)$ \\
\hline \multicolumn{3}{|l|}{ Bowel preparation, $\mathrm{n}(\%)$} \\
\hline Good & $66(72)$ & 73 (78) \\
\hline Fair & $26(28)$ & $21(22)$ \\
\hline Adverse event rate & $1 / 92$ & $0 / 94$ \\
\hline
\end{tabular}

in the WLE group underwent a colectomy because of CRC compared with none in the CE group. After the 2year procedure, 4 patients underwent colectomy because of CRC. No serious adverse events as a consequence of the endoscopic procedures were observed in either group throughout the study period.

\section{DISCUSSION}

In this randomized controlled study in patients with LS who were under surveillance, we found that neoplasia detection rates were similar between WLE and CE, both at baseline colonoscopy and at the follow-up colonoscopy after 2 years. Although CE in the proximal colon was associated with higher polyp detection rates at baseline, neoplasia detection rates were similar. This is partly in accordance with previous findings. ${ }^{7,18-20}$ So far, 4 studies have prospectively assessed the value of CE in LS.,18-20 In 3 studies, a conventional colonoscopy was directly followed by colonoscopy with proximal $\mathrm{CE}^{18}$ or pancolonic CE. ${ }^{19,20}$ These studies all showed that with the second withdrawal by $\mathrm{CE}$, additional adenomas were detected. ${ }^{18-20}$ One study demonstrated that significantly more adenomas were detected per patient ( 0.3 per patient in CE vs 0.1 per patient in WLE). ${ }^{19}$ However, these 3 studies are hampered by a back-to-back study design. ${ }^{18-20}$ In such a study design, the colon of a particular patient is examined twice in 1 procedure and this probably introduced bias, because a second look will almost always detect additional adenomas. Therefore, it is difficult to compare the outcomes of these previous studies with our study results. In another CE study, the patients were randomized after conventional WLE to an immediate second examination with either CE or WLE using a sophisticated back-to-back-design. ${ }^{7}$ No significant difference in 


\begin{tabular}{|c|c|c|c|}
\hline & $\begin{array}{c}\text { White-light } \\
\text { endoscopy } \\
\text { group } \\
(n=92) \\
n(\%)\end{array}$ & $\begin{array}{c}\text { Chromoendoscopy } \\
\text { group } \\
(n=94) \\
n(\%)\end{array}$ & $\begin{array}{c}P \\
\text { value }\end{array}$ \\
\hline Patients with polyp(s) & $54(59)$ & $38(40)$ & .013 \\
\hline Patients with neoplasia & $24(26)$ & $26(28)$ & .80 \\
\hline $\begin{array}{l}\text { Patients with advanced } \\
\text { neoplasia }\end{array}$ & $5(5)$ & $5(5)$ & .77 \\
\hline $\begin{array}{l}\text { Patients with proximal } \\
\text { polyps }\end{array}$ & $41(45)$ & $31(32)$ & .11 \\
\hline $\begin{array}{l}\text { Patients with proximal } \\
\text { neoplasia }\end{array}$ & $20(22)$ & $21(22)$ & .92 \\
\hline
\end{tabular}

adenoma detection was found, but the yield with respect to subsequent polyp detection in the second procedure was significantly higher with CE compared with WLE. ${ }^{7}$ Recently a well-designed prospective randomized controlled trial in 61 patients with LS showed a significantly higher adenoma miss rate for HD WLE compared with virtual CE/I-SCAN independently of inspection time. $^{26}$ Thus, most of the evidence suggests that CE increases polyp detection in LS, but data are conflicting regarding the effect of $\mathrm{CE}$ on the detection of neoplastic lesions.

We found no difference in neoplasia detection rates between CE and WLE at the baseline investigation. Based on the literature, it was expected that the neoplasia detection rate at baseline would be around 20\% using WLE, and that the rate for $\mathrm{CE}$ would be double that. What we found was that the neoplasia detection rate was actually higher than expected in the WLE group (27\%) and lower than expected in the CE group (30\%). The question is why CE of the proximal colon was not associated with a difference in neoplasia detection rates, although we found a trend toward higher neoplasia detection rates in the proximal colon at the baseline investigation using CE (24\%) versus WLE (18\%). We cannot rule out the possibility that our study was insufficiently powered to demonstrate a difference. Another explanation may lie in the fact that in about half of the baseline procedures, HD colonoscopes were used, which may have contributed to the relatively high neoplasia detection rate in the WLE group. This may have introduced some bias because a higher adenoma detection rate has been demonstrated with HD whitelight colonoscopy compared with conventional whitelight colonoscopy, ${ }^{12,15}$ although this was not observed in our data.

It may well be that the additional value of $\mathrm{CE}$ is negligible in procedures where HD devices are used, as was recently demonstrated in surveillance of patients with inflammatory bowel disease. ${ }^{27,28}$ Another explanation why
TABLE 7. Clinicopathologic features of lesions detected at 2-year colonoscopy

\begin{tabular}{|c|c|c|}
\hline & $\begin{array}{c}\text { White-light } \\
\text { endoscopy } \\
\text { group ( } n=92)\end{array}$ & $\begin{array}{l}\text { Chromoendoscopy } \\
\text { group }(n=94)\end{array}$ \\
\hline Total number of lesions & 99 & 88 \\
\hline $\begin{array}{l}\text { Total number of neoplastic } \\
\text { lesions }\end{array}$ & 39 & 37 \\
\hline \multicolumn{3}{|c|}{ Number of neoplastic lesions according to histology } \\
\hline $\begin{array}{l}\text { Adenoma with low-grade } \\
\text { dysplasia }\end{array}$ & 36 & 34 \\
\hline $\begin{array}{l}\text { Adenoma with high-grade } \\
\text { dysplasia }\end{array}$ & 2 & 0 \\
\hline $\begin{array}{l}\text { Adenoma with serrated } \\
\text { histology (traditional } \\
\text { serrated adenoma) }\end{array}$ & 0 & 0 \\
\hline Carcinoma & 1 & 3 \\
\hline Advanced neoplastic lesions & 5 & 5 \\
\hline \multicolumn{3}{|c|}{ Number of neoplastic lesions according to location } \\
\hline Proximal & 34 & 30 \\
\hline Distal & 5 & 7 \\
\hline \multicolumn{3}{|c|}{ Number of adenomas according to size } \\
\hline$\leq 5 \mathrm{~mm}$ & 27 & 26 \\
\hline $6-9 \mathrm{~mm}$ & 9 & 6 \\
\hline$\geq 10 \mathrm{~mm}$ & 2 & 2 \\
\hline $\begin{array}{l}\text { Number of non-neoplastic } \\
\text { lesions }\end{array}$ & 60 & 51 \\
\hline \multicolumn{3}{|c|}{ Number of non-neoplastic lesions according to histology } \\
\hline Sessile serrated polyp & 29 & 13 \\
\hline Proximal $<5 \mathrm{~mm}$ & 10 & 5 \\
\hline Proximal 6-9 mm & 5 & 1 \\
\hline Proximal $>10 \mathrm{~mm}$ & 1 & 0 \\
\hline Distal & 13 & 7 \\
\hline $\begin{array}{l}\text { Other (lymphoid tissue, normal } \\
\text { mucosa) }\end{array}$ & 31 & 38 \\
\hline
\end{tabular}

detection rates were similar between CE and WLE may be the relatively high proportion of MSH6 mutation carriers (approximately 40\%) in this study. These persons have a significantly lower cumulative CRC risk compared with MLH1 and MSH2 mutation carriers. ${ }^{6}$ By including a relatively large group of $M S H 6$ mutation carriers possibly fewer adenomas were detected than expected.

Optimization of adenoma detection by CE and subsequent removal at the initial colonoscopy could be important for patients, because it may reduce the incidence of neoplasia during follow-up. Our study is the first to our knowledge in which the effect of CE on neoplasia detection was examined in 2 consecutive colonoscopy procedures over a 2-year observation period. Our results after 2 years did not demonstrate that $\mathrm{CE}$ has a benefit over 


\begin{tabular}{|c|c|c|c|c|}
\hline Age (years), gender & 66 , female & 30 , male & 47, female & 54 , female \\
\hline Tumor location & Ascending & Ascending & Ascending & Ascending \\
\hline Interval between procedures (months) & 22 & 26 & 28 & 22 \\
\hline Tumor stage & 1 & III & 1 & 1 \\
\hline Chromoendoscopy at baseline procedure & No & Yes & Yes & Yes \\
\hline Findings at baseline procedure & 3 proximal adenomas & No abnormalities & 2 proximal adenomas & 3 proximal adenomas \\
\hline High-definition scope used at baseline procedure & Yes & No & No & No \\
\hline
\end{tabular}

WLE in the ability to reduce the occurrence of colorectal neoplasia during surveillance. Our follow-up data are limited to a period of only 2 years, which is probably too short to detect a possible protective effect of CE on the incidence of colorectal neoplasia. Clearly, long-term follow-up studies are warranted to determine whether CE is indeed able to reduce CRC risk in patients with LS.

Our study has several strengths. It is the largest $\mathrm{CE}$ study in proven MMR gene mutation carriers thus far. We stratified patients according to the presence or absence of adenomas during previous procedures, a strategy that was not applied in earlier studies. The aim here was to reduce potential bias introduced by the fact that some patients may develop neoplasia more rapidly than others. As mentioned before, our study is novel in that it is the first to prospectively assess the possible influence of $\mathrm{CE}$ on the detection of colorectal neoplasia during follow-up, including a 2-year observation period.

Our study has some limitations apart from the confounding factor introduced by the use of HD devices in a subset of patients. One is that the study was powered to detect a difference in neoplasia detection rate at baseline based on previous pancolonoscopy CE detection rates, whereas in fact only the proximal colon was investigated by $\mathrm{CE}$, as we expected the highest yield of the technique in this part of the colon. This calls for caution when interpreting the results. Another limitation of our study was that we did not use a validated scale to assess bowel preparation. Finally, the classification of sessile serrated lesions as non-neoplastic lesions in our study may be disputed. It must be realized that the currently widely used 2010 World Health Organization classification of this type of lesions ${ }^{29}$ had not yet been published when our study was designed. The role of the sessile serrated pathway in LS is unclear but may be comparable with that in the general population. $^{29}$

In conclusion, although CE increased the detection rate of colorectal lesions in patients with LS at baseline, detection rates of colorectal neoplasia were similar between the groups both at baseline and at the follow-up colonoscopy after 2 years. Our results do not clearly support a benefit of CE over white-light colonoscopy during surveillance in patients with LS, although long-term follow-up studies are warranted to determine whether CE is able to reduce CRC risk.

\section{REFERENCES}

1. Lynch HT, Lynch PM, Lanspa SJ, et al. Review of the Lynch syndrome: history, molecular genetics, screening, differential diagnosis, and medicolegal ramifications. Clin Genet 2009;76:1-18.

2. Koornstra JJ, Mourits MJ, Sijmons RH, et al. Management of extracoIonic tumours in patients with Lynch syndrome. Lancet Oncol 2009;10:400-8.

3. Järvinen HJ, Aarnio M, Mustonen $\mathrm{H}$, et al. Controlled 15-year trial on screening for colorectal cancer in families with hereditary nonpolyposis colorectal cancer. Gastroenterology 2000;118:829-34.

4. Vasen HF, Abdirahman M, Brohet R, et al. One to 2-year surveillance intervals reduce risk of colorectal cancer in families with Lynch syndrome. Gastroenterology 2010;138:2300-6.

5. de Jong AE, Hendriks YM, Kleibeuker JH, et al. Decrease in mortality in Lynch syndrome families because of surveillance. Gastroenterology 2006;130:665-71.

6. Møller P, Seppälä T, Bernstein I, et al. Cancer incidence and survival in Lynch syndrome patients receiving colonoscopic and gynaecological surveillance: first report from the prospective Lynch syndrome database. Gut 2017;66:464-72.

7. Stoffel EM, Turgeon DK, Stockwell DH. Missed adenomas during colonoscopic surveillance in individuals with Lynch Syndrome (hereditary nonpolyposis colorectal cancer). Cancer Prev Res 2008;1:470-5.

8. Rondagh EJA, Gulikers S, Gómez-Garcia EB, et al. Nonpolypoid colorectal neoplasms: a challenge in endoscopic surveillance of patients with Lynch syndrome. Endoscopy 2013;45:257-64.

9. Rijcken FE, Hollema H, Kleibeuker JH. Proximal adenomas in hereditary non-polyposis colorectal cancer are prone to rapid malignant transformation. Gut 2002;50:382-6.

10. Heresbach D, Barrioz T, Lapalus MG, et al. Miss rate for colorectal neoplastic polyps: a prospective multicenter study of back-to-back video colonoscopies. Endoscopy 2008;40:284-90.

11. Haanstra JF, Kleibeuker JH, Koornstra JJ. Role of new endoscopic techniques in Lynch syndrome. Fam cancer 2013;12:267-72.

12. Hazewinkel Y, Dekker E. Colonoscopy: basic principles and novel techniques. Nat Rev Gastroenterol Hepatol 2011;8:554-64.

13. Brown SR, Baraza W. Chromoscopy versus conventional endoscopy for the detection of polyps in the colon and rectum. Cochrane Database Syst Rev 2010;10:CD006439.

14. Park SY, Lee SK, Kim BC, et al. Efficacy of chromoendoscopy with indigo carmine for the detection of ascending colon and cecum lesions. Scand J Gastroenterol 2008;43:878-85. 
15. Kaminski MF, Hassan C, Bisschops R, et al. Advanced imaging for detection and differentiation of colorectal neoplasia: European Society of Gastrointestinal Endoscopy (ESGE) Guideline. Endoscopy 2014;46: 435-49.

16. Rutter MD, Saunders BP, Schofield G, et al. Pancolonic indigo carmine dye spraying for the detection of dysplasia in ulcerative colitis. Gut 2004;53:256-60.

17. Marion JF, Waye JD, Present DH, et al. Chromoendoscopy-targeted biopsies are superior to standard colonoscopic surveillance for detecting dysplasia in inflammatory bowel disease patients: a prospective endoscopic trial. Am J Gastroenterol 2008;103: 2342-9.

18. Lecomte T, Cellier C, Meatchi T, et al. Chromoendoscopic colonoscopy for detecting preneoplastic lesions in hereditary nonpolyposis colorectal cancer syndrome. Clin Gastroenterol Hepatol 2005;3: 897-902.

19. Huneburg R, Lammert F, Rabe C, et al. Chromocolonoscopy detects more adenomas than white light colonoscopy or narrow band imaging colonoscopy in hereditary nonpolyposis colorectal cancer screening. Endoscopy 2009;41:316-22.

20. Rahmi G, Lecome T, Maika D, et al. Impact of chromoscopy on adenoma detection in patients with Lynch syndrome: a prospective, multicenter, blinded, tandem colonoscopy study. Am J Gastroenterol 2015;110:288-98.

21. Lieberman D, Nadel M, Smith RA, et al. Standardized colonoscopy reporting and data system: report of the Quality Assurance Task Group of the National Colorectal Cancer Roundtable. Gastrointest Endosc 2007;65:757-66.
22. Endoscopic Classification Review Group. Update on the Paris classification of superficial neoplastic lesions in the digestive tract. Endoscopy 2005;37:570-8.

23. Dove-Edwin I, de Jong AE, Adams J, et al. Prospective results of surveillance colonoscopy in dominant familial colorectal cancer with and without Lynch syndrome. Gastroenterology 2006;130:1995-2000.

24. East JE, Suzuki N, Stavrinidis M, et al. Narrow band imaging for colonoscopic surveillance in hereditary non-polyposis colorectal cancer. Gut 2008;57:65-70.

25. Browner WS, Newman TB, Hulley SB. Estimating sample size and power: applications and examples. In: Hulley SB, Cummings SR, Browner WS, et al, editors. Designing clinical research. Philadelphia: Lippincott Williams \& Wilkins; 1993. p. 65-94.

26. Bisschops R, Teipar S, Willekens $H$, et al. Virtual chromoendoscopy (I-scan) detects more polyps in patients with Lynch syndrome: a randomized controlled crossover trial. Endoscopy 2017;49:342-50.

27. lacucci M, Kaplan GG, Panaccione $R$, et al. A randomized trial comparing high definition colonoscopy alone with high definition dye spraying and electronic virtual chromoendoscopy for detection of colonic neoplastic lesions during IBD surveillance colonoscopy. Am J Gastroenterol 2018;113:225-34.

28. Ten Hove JR, Bernstein CN, Oldenburg B. Putting evidence into practice: IBD surveillance, chromoendoscopy and future directions. Am J Gastroenterol 2018;113:313-6.

29. Vleugels JLA, Sahin H, Hazewinkel Y, et al. Endoscopic detection rate of sessile serrated lesions in Lynch syndrome patients is comparable to an age- and gender-matched control population: case-control study with expert pathology review. Gastrointest Endosc 2018;87:1289-96.

Access to Gastrointestinal Endoscopy Online is reserved for all subscribers!

Full-text access to Gastrointestinal Endoscopy Online is available for all subscribers. ASGE MEMBER SUBSCRIBERS: To activate your individual online subscription, please visit http://www.asge.org and follow the instructions. NONMEMBER SUBSCRIBERS: To activate your individual online subscription, please visit http://www. giejournal.org and follow the prompts to activate your online access. To activate your account, you will need your subscriber account/membership number, which you can find on your mailing label (note: the number of digits in your subscriber account number varies from 6 to 10 digits). See the example below in which the subscriber account number has been circled:

Sample mailing label

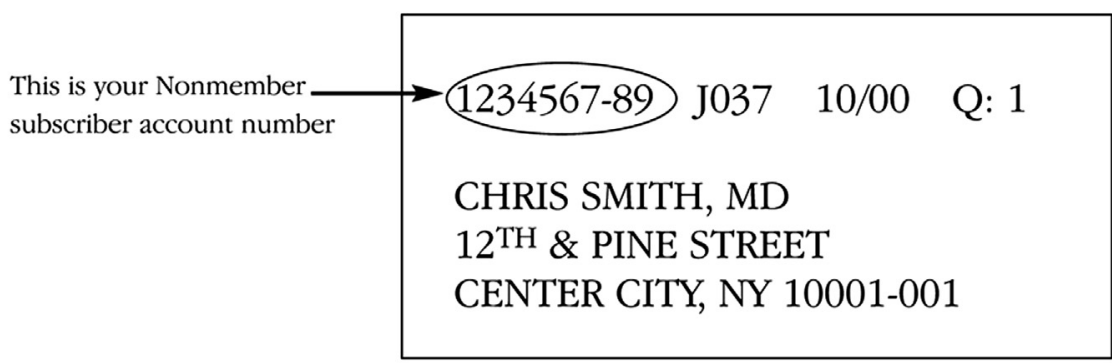

Personal subscriptions to Gastrointestinal Endoscopy Online are for individual use only and may not be transferred. Use of Gastrointestinal Endoscopy Online is subject to agreement to the terms and conditions as indicated online. 